\title{
Mean and Fluctuating Pressure in Boat-Tail Separated Flows at Transonic Speeds
}

\author{
Rajan Kumar* and P. R. Viswanath ${ }^{\dagger}$ \\ National Aerospace Laboratories, Bangalore 560 017, India \\ and \\ A. Prabhu ${ }^{\ddagger}$ \\ Indian Institute of Science, Bangalore 560012 , India
}

\begin{abstract}
Experiments were carried out investigating the features of mean and unsteady surface pressure fluctuations in boat-tail separated flows relevant to launch vehicle configurations at transonic speeds. The tests were performed on a generic axisymmetric body in the Mach-number range of $0.7-1.2$, and the important geometrical parameters, namely, the boat-tail angle and diameter ratio, were varied systematically. The measurements made included primarily the mean and unsteady surface-pressure fluctuations on nine different model configurations. Flowvisualization studies employing a surface oil flow, and schlieren techniques were carried out to infer features like boundary-layer separation, reattachment, and shock waves in the flow. The features of mean and fluctuating surface pressures are discussed in detail including aspects of similarity. It has been observed that, on a generic configuration employed in the present study, the maximum levels of surface-pressure fluctuations in the reattachment zone are appreciably lower than those found on launch vehicle configurations having a bulbous or hammerhead nose shape. A simple correlation is suggested for the maximum value of rms pressure fluctuations in the reattachment zone at different freestream Mach numbers.
\end{abstract}

\begin{tabular}{|c|c|}
\hline & Nomencláture \\
\hline$C_{p}$ & $=$ static-pressure coefficient, $\left(p-p_{s}\right) / q_{s}$ \\
\hline$C_{\text {prms }}$ & $=$ unsteady surface-pressure coefficient, $p_{\text {rms }} / q_{s}$ \\
\hline$C_{\text {prms (BL) }}$ & $\begin{aligned}= & C_{\text {prms }} \text { for attached boundary layer } \\
& (\text { at } x / D=-0.33)\end{aligned}$ \\
\hline$C_{\text {prms (max) }}$ & $=$ maximum value of $C_{\text {prms }}\left(\right.$ at $\left.x_{r}\right)$ \\
\hline$C_{\mathrm{prms}, \infty}$ & $\begin{aligned}= & \text { unsteady surface-pressure coefficient } \\
& \text { based on freestream conditions, } p_{\text {rms }} / q_{\infty}\end{aligned}$ \\
\hline$D$ & $=$ forebody diameter $(90 \mathrm{~mm})$ \\
\hline$d$ & $=$ rear-body diameter \\
\hline$h$ & $=$ step height, $(D-d) / 2$ \\
\hline$M$ & $=$ Mach number \\
\hline$p$ & $=$ local static pressure \\
\hline$p^{\prime}$ & $=$ pressure fluctuation \\
\hline$p_{\text {rns }}$ & $=\mathrm{rms}$ pressure fluctuation \\
\hline$q$ & $=$ dynamic pressure, $0.5 \gamma p M^{2}$ \\
\hline$R$ & $=$ reattachment location \\
\hline$S$ & $=$ separation location \\
\hline$u$ & $=$ local velocity \\
\hline$u *$ & $=$ friction velocity \\
\hline$x$ & $=$ streamwise distance $(x=0$ at boat-tail corner $)$ \\
\hline$x_{r}$ & $=$ reattachment distance \\
\hline$y$ & $=$ distance normal to the surface \\
\hline$\beta$ & $=$ boat-tail angle \\
\hline$\Delta C_{\mathrm{prms}}$ & $=C_{\mathrm{prms}(\max )}-C_{\mathrm{prms}(\mathrm{BL})}$ \\
\hline & $=$ boundary-layer thickness at $x=-30 \mathrm{~mm}$ \\
\hline
\end{tabular}

\section{Subscripts}

$s \quad=$ reference conditions (at $x / D=-1.0)$

$\infty$

\section{Introduction}

$\mathbf{T}$ HE relatively high levels of surface-pressure fluctuations arising in zones of turbulent boundary-layer separation, reattachment; and shock-wave-boundary-layer interaction can be a source of buffet excitation of a flight vehicle structure, particularly at transonic speeds. ${ }^{1-4}$ The effects are amplified in the presence of a normal shock wave at transonic Mach numbers. Even though it is desirable to have a shape that would maintain an attached boundary layer over most of the vehicle surface, space vehicle configurations are not aerodynamically clean because of certain design requirements and have shapes that disturb the flow causing local shocks, regions of flow separation, and highly disturbed attached flow.

In the context of a launch vehicle having a bulbous or hammerhead nose shape, buffeting caused by the aerodynamic excitation in the nose as well as boat-tail regions of the configuration has been of significant concern in design. ${ }^{1-4}$ The boat-tail region of a launch vehicle leads to separation of flow, and relatively high levels of pressure fluctuations occur in the reattachment zone. Pressure fluctuations in the nose region are essentially caused by unsteady shock waves, which are localized. At higher transonic Mach numbers $\left(1.0 \leq M_{\infty} \leq 1.2\right)$ the flow over the launch vehicle configuration becomes supersonic, and the shock gets shifted downstream. The boat-tail region takes added emphasis because vital electronic instruments are often housed in that zone, and vibrations transmitted into the structure can affect the performance of such equipment.

In most earlier studies, ${ }^{1-4}$ particularly involving launch-vehicletype configurations, not much attention has been given to aspects of shear-layer reattachment (following separation at boat-tail corner); in particular, the data available on pressure fluctuations in the reattachment zone as influenced by the important geometrical parameters such as diameter ratio (or step height), boat-tail angle, and flow parameters such as the Reynolds number and Mach number are very limited. Furthermore, difficulty exists in modeling turbulence in complex flows involving strong adverse pressure gradients, shock waves, and three-dimensionality, and therefore estimates of the aerodynamic excitation caused by separated flows for design needs would depend on engineering methods, which are based on a good database.

The present study is an attempt to understand certain major features of mean and unsteady surface-pressure fluctuations in boat-tail separated flows relevant to launch vehicle configurations. The experimental results have enabled a clear description of the major effects 
each pressure transducer was connected to the static-pressure port locáted at same longitudinal position adjacent to it, balancing out the steady pressure across the transducer diaphragm. However, to prevent the unsteady pressure from acting on the reference side of the diaphragm a suitable damper was designed and connected between the reference side of the transducer and the static-pressure port.

The use of the preceding scheme ensured that the transducer output will be essentially caused by the unsteady pressure on the flow side of its diaphragm and enabled the use of a lower range transducer and also a high amplifier gain tailored primarily for the unsteady pressure levels. Another important feature of instrumentation scheme used was the use of small sized, fixed gain booster amplifiers to improve the signal-to-noise ratio. These amplifiers were housed within the model and located as close as possible to the pressure transducers. Outputs from these booster amplifiers were fed to the signal conditioners placed outside the tunnel. Other precautions taken to reduce the noise were the use of battery for the excitation of pressure transducers. Adoption of the various measures just noted resulted in a high signal-to-noise ratio. More details of the instrumentation used are reported in Ref. 6.

\section{- Measurement Uncertainties}

The uncertainty in the steady pressure measurements was estimated using the method suggested by Kline and McClintock. The estimated uncertainty taking into account of repeatability was $\Delta C_{p}< \pm 0.02 C_{p}$. In the context of unsteady pressure measurements, the major sources of error include transducer measurement accuracy, transducer flushness, instrumentation noise, flow unsteadiness in the tunnel, and the record length. As already indicated, the Kulite transducers were,statically calibrated, and the uncertainty obtained from static calibration was within $\pm 1 \%$ of full scale. Sufficient care was taken to mount the transducers flush to the surface. The pressure fluctuation data include the contribution caused by the inevitable flow unsteadiness in the tunnel. Unsteady pressure signals were acquired at a sampling frequency of $25.6 \mathrm{kHz}$ for about $8 \mathrm{~s}$ for obtaining the rms value and spectra of pressure fluctuations. The maximum uncertainty in the measurement of unsteady pressure coefficient, taking into account of repeatability, was estimated to be within $\pm 5 \%$.
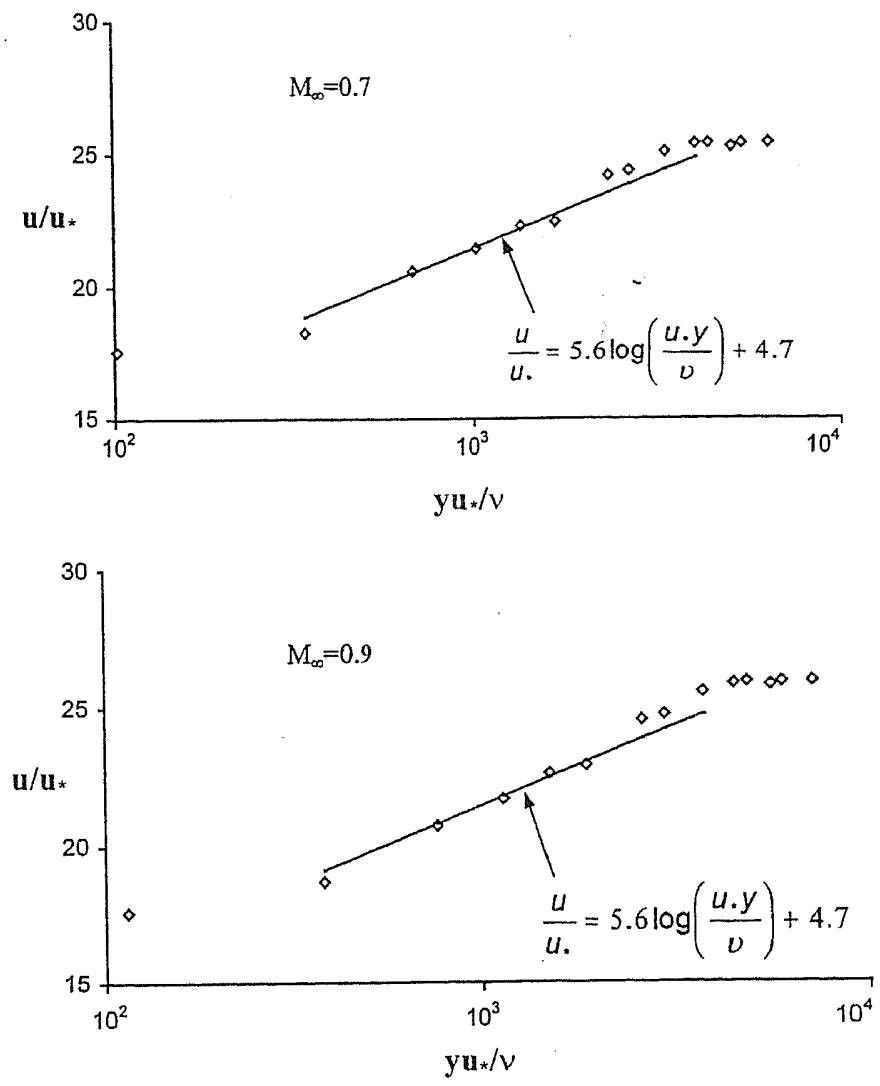

Fig. 3 Mean velocity profiles in wall coordinates.

\section{Results and Discussion}

Boundary-Layer Properties

The boundary-layer mean velocity profiles (ahead of boat-tail corner on the forebody) at $x=-30 \mathrm{~mm}$ were measured using a pitorrake in the Mach-number range of $0.7-1.0$; the streamwise location of the rake was chosen to be in the zero-pressure-gradient zone, as we shall discuss in detail subsequently. The measured boundary-layer thickness $\delta_{0}$ at the different freestream Mach numbers was essentially constant around $6 \mathrm{~mm}$. The associated transverse parameter $\delta_{0} / R \approx 0.13$ (where $R$ is the forebody radius) is quite small, and therefore the boundary-layer properties might be expected to be similar to those in two-dimensional flows. The measured velocity profiles (Fig. 3) at different freesteam Mach numbers display a sizable logarithmic region suggesting that the turbulent boundary layer ahead of boat-tail is reasonably well developed. ${ }^{8}$

\section{Surface Flow Visualization}

Typical surface flow-visualization photographs on three boat-tail configurations for the diameter ratio of 0.65 and a a Mach number of 0.8 are shown in Fig. 4 (the vertical line at location $\mathrm{A}$ in Fig. $4 \mathrm{a}$ is a weak tool mark and does not represent any flow feature). The boundary-layer separation generally occurred at the boat-tail comer and reattachment downstream on the cylinder at a distance, which depended on the diameter ratio $d / D$, boat-tail angle $\beta$, and $M_{\infty}$. Although the test configuration is axisymmetric, a small degree of circumferential variation in the location of reattachment was seen in some cases; the presence of three-dimensional perturbations in

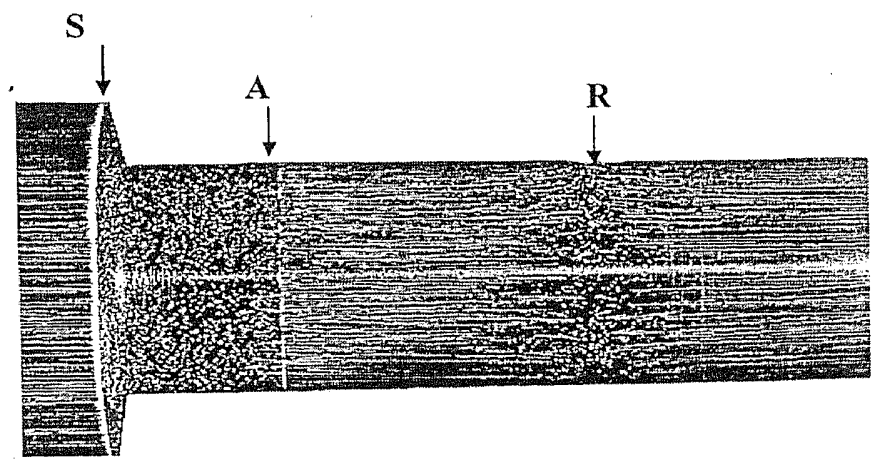

a) $d / D=0.65, \beta=90 \mathrm{deg}, M_{\infty}=0.8$

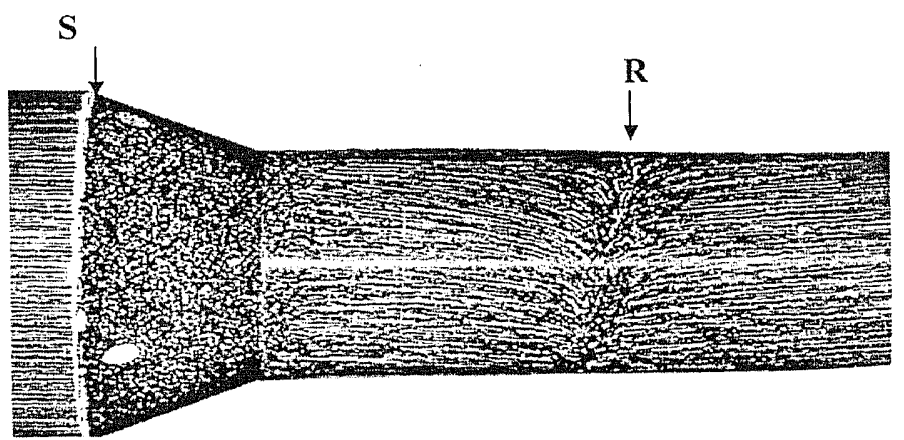

b) $d / D=0.65, \beta=31.5 \mathrm{deg}, M_{\infty}=0.8$

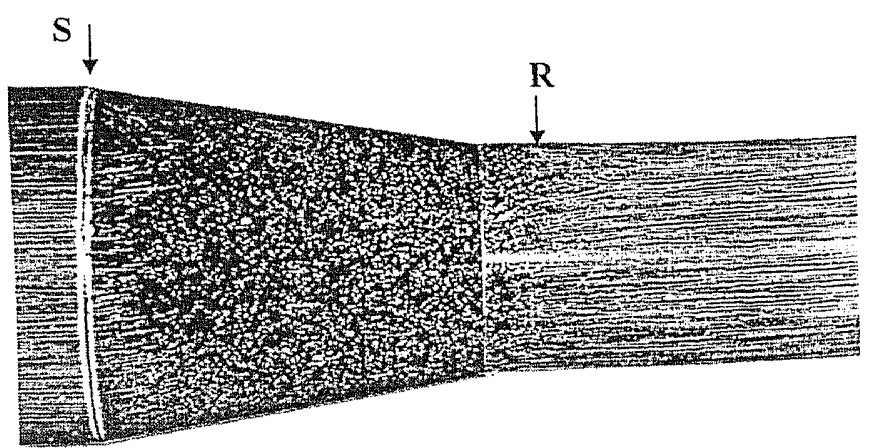

c) $d / D=0.65, \beta=15 \mathrm{deg}, M_{\infty}=0.8$

Fig. 4 Typical surface flow-visualization photographs. 
nominally two-dimensional separated flows are not uncommon. 19. In contrast to the preceding observations, at $M_{x}=1.0$ and 1.2 and $\beta=15$ deg the separation of the boundary layer occurred along the boat-tail surface.

\section{Schlieren Flow Visualization}

The schlieren photographs were taken in the $M_{\infty}$ range of $0.8-1.2$ to capture certain broad features of separated fow and presence of shock waves in the flow (Fig. 5). Although boundary-layer sepa-

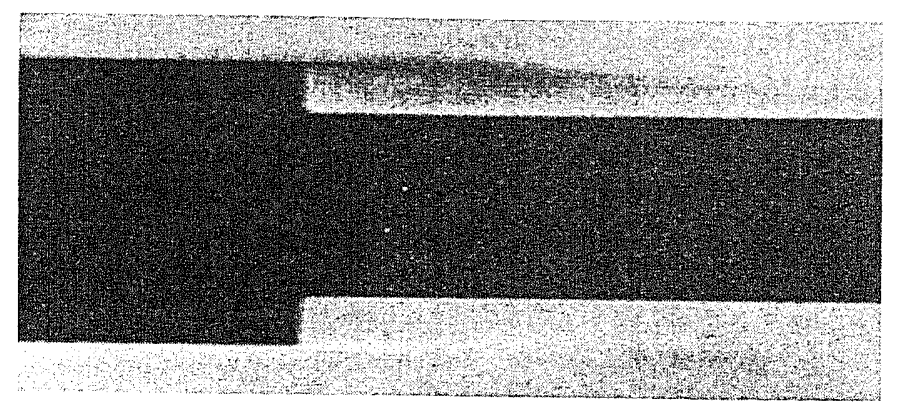

a) $d / D=0.65, \beta=90 \mathrm{deg}, M_{\infty}=0.8$

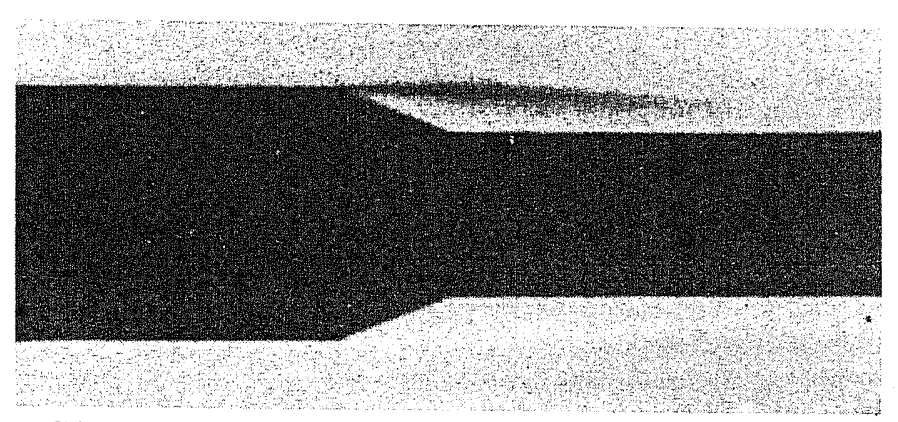

b) $d / D=0.65, \beta=31.5 \mathrm{deg}, M_{\infty}=0.8$

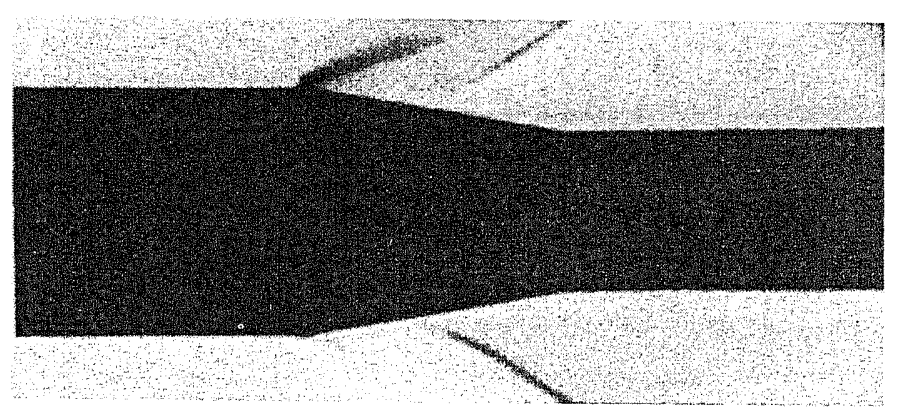

c) $d / D=0.65, \beta=15 \mathrm{deg}, M_{\infty}=1.0$

Fig. 5 Typical schlieren flow-visualization photographs. ration generally occurred at the boat-tail comer and reattachment downstream on the cylinder in most cases (Figs. 5a and 5b), the presence of a shock wave and subsequent separation of the boundary layer in the boat-tail region can be seen for the configuration with $\beta=15$ deg (Fig. 5c).

Classification of Boat-Tail Flows

Over the range of Mach numbers and different model configurations studied, two types of boat-tail flows were observed (Fig. 6); 1) boundary-layer separation at the boat-tail corner with shear-layer reattachment downstream on the cylinder surface for most of the configurations (type I) and 2) shock-induced boundary-layer separation along the boat-tail with subsequent reattachment on the cylinder surface (type II.) for few cases involving low $\beta(=15 \mathrm{deg})$ and at freestream Mach numbers of 1.0 and 1.2.

\section{Mean Surface-Pressure Distributions}

In what follows, we shall present the measured surface-pressure distributions in terms of $C_{p}$ [defined as $\left(p-p_{s}\right) / q_{s}$ ]. Because the turbulent boundary layer grows under a nearly zero-pressuregradient condition ahead of the boat-tail corner, it is meaningful and appropriate to define a surface-pressure coefficient $C_{p}$ based on these (local) conditions on the cylinder $\left(M_{s}\right.$ and $\left.p_{s}\right)$ measured at $x / D=-1.0$ rather than $M_{\infty}$ and $p_{\infty}$.

A typical plot of surface-pressure distribution on the complete model for $d / D=0.65$ and $\beta=31.5 \mathrm{deg}$ at $M_{\infty}=0.8$ is shown in Fig. 7. As might be expected, the flow accelerates on the tangent ogive surface, reaches a minimum around the ogive-cylinder junction, and is then recompressed to a nearly constant pressure along the cylindrical portion of the body. The lower surface pressures in the boat-tail region are the result of boundary-layer separation at the corner. The subsequent increase in surface pressures indicates

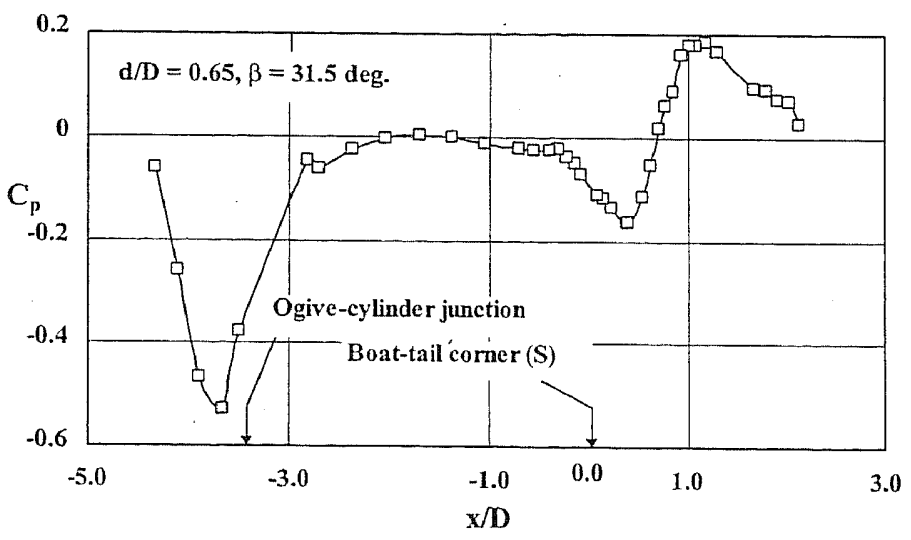

Fig. 7 Typical static-pressure distribution at $M_{\infty}=0.8$.

\section{CLASSIFICATION OF BOAT-TAIL FLOWS}

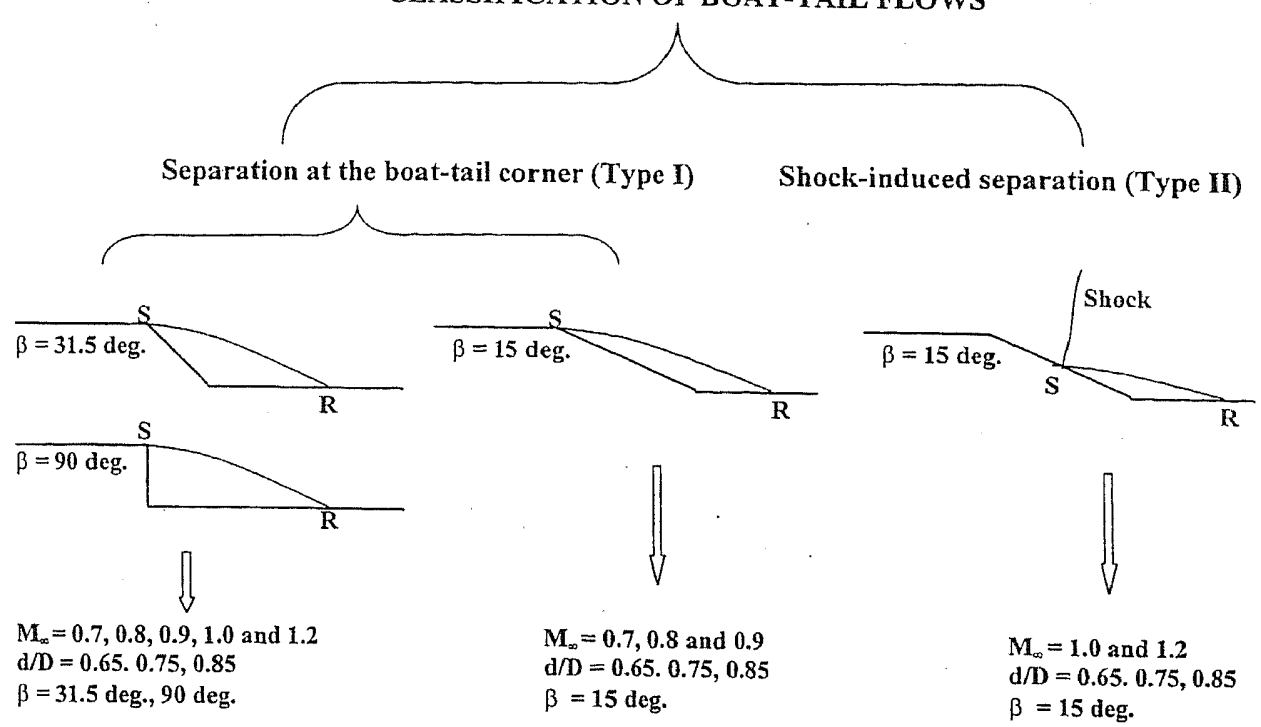

Fig. 6 Schematic of boat-tail flows observed. 


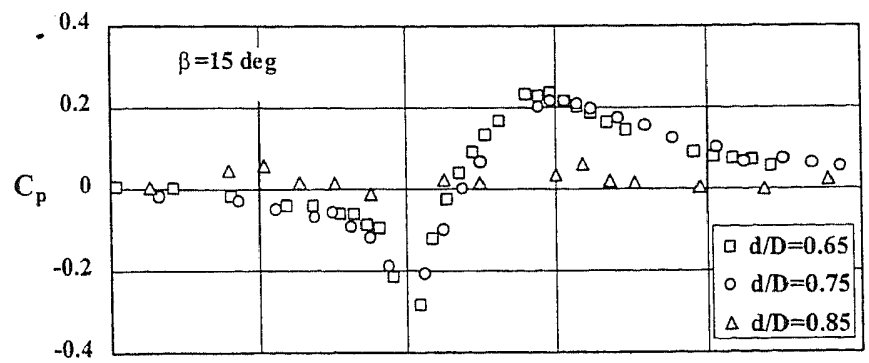

a)

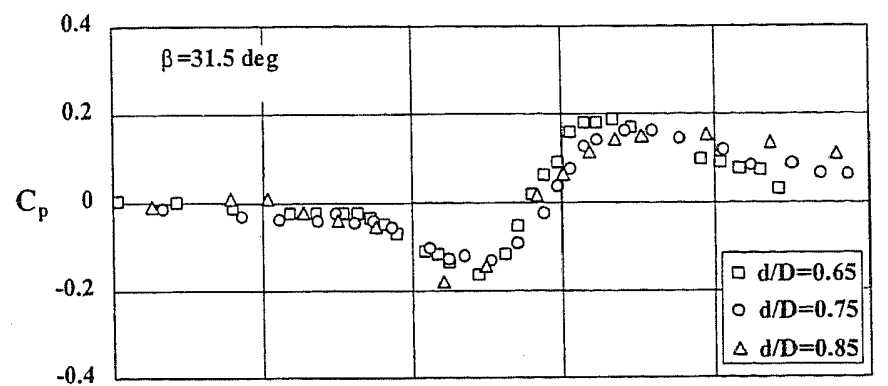

b)

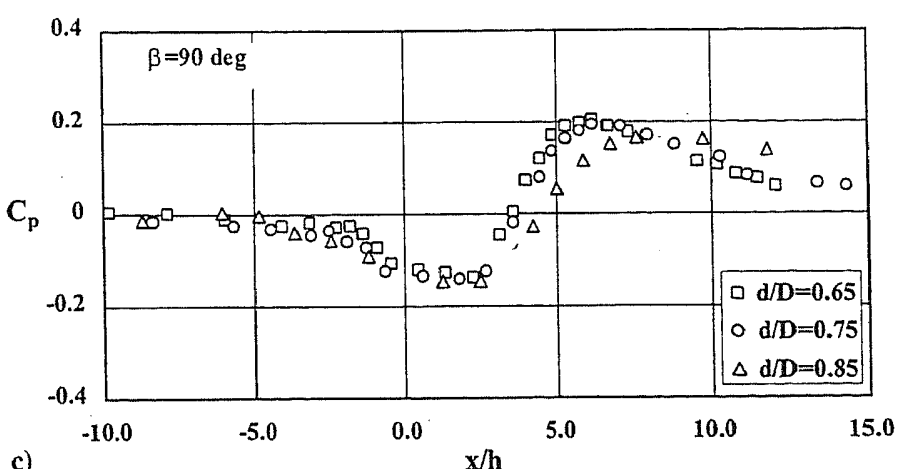

Fig. 8 Effect of diameter ratio on surface-pressure distributions, $M_{\infty}=0.8$.

reattachment of the separated flow, reaching a maximum and relaxing gradually to the freestream static pressure.

\section{Effect of Diameter Ratio and Boat-Tail Angle}

First, we will discuss the features for type I flow for which flow separates on the boat-tail corner and reattaches on the cylinder downstream. The mean surface-pressure distributions in the boattail zone for the type I flow were qualitatively similar on all of the configurations and Mach numbers tested (Figs. 8-10), except for the case of $d / D=0.85$ and $\beta=15 \mathrm{deg}$, for which the pressure changes were weak because the step height $h$ is small and the boat-tail angle is shallow; the surface flow visualization showed a weakly separated flow. ${ }^{6}$ In such a case the gross features of the flow will be essentially those of an attached flow leading to a weak perturbation in surface-pressure distribution, as observed in experiments.

Figure 8 shows the effect of diameter ratio at fixed values of $\beta$ at $M_{\infty}=0.8$. The results show that the step height $h$, associated with the boat-tail angle $\beta$, is a useful length scale to normalize the streamwise distance in the description of the surface-pressure distributions (Fig. 8); this is to be expected from our knowledge of base flow dynamics. ${ }^{11-13}$ The use of the distance to reattachment from separation $x_{r}$ resulted in a significant collapse of the pressure distributions for a given $\beta$ (Fig. 9). Figure 10 shows the effect of $\beta$ on $C_{p}$ distributions for a given diameter ratio and Mach number; interestingly, the results are seen to be essentially the same, in a nondimensional sense, for $\beta=31.5$ and 90 deg suggesting relatively weak effects of $\beta$ beyond $31.5 \mathrm{deg}$. The preceding features of similarity were found at other Mach numbers as well. ${ }^{6}$

For type II flows involving shock-induced separation along the boat-tail and reattachment downstream, the pressure distributions were broadly similar to type I flows. ${ }^{6}$ Figure 11 shows the effect

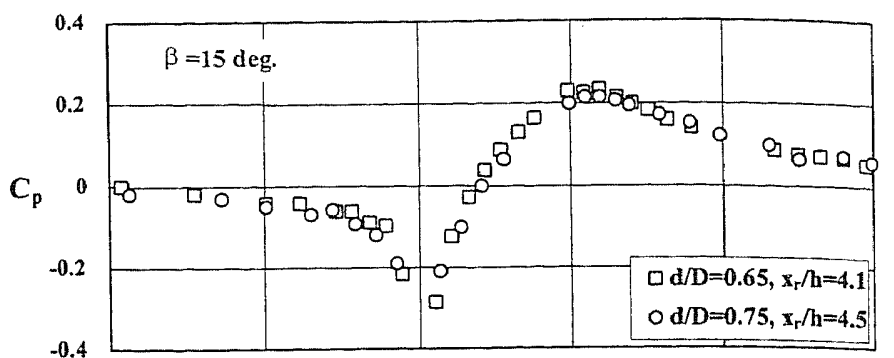

a)

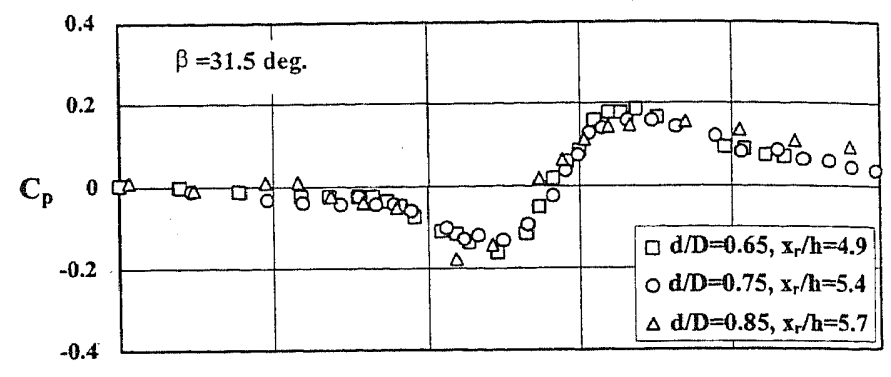

b)

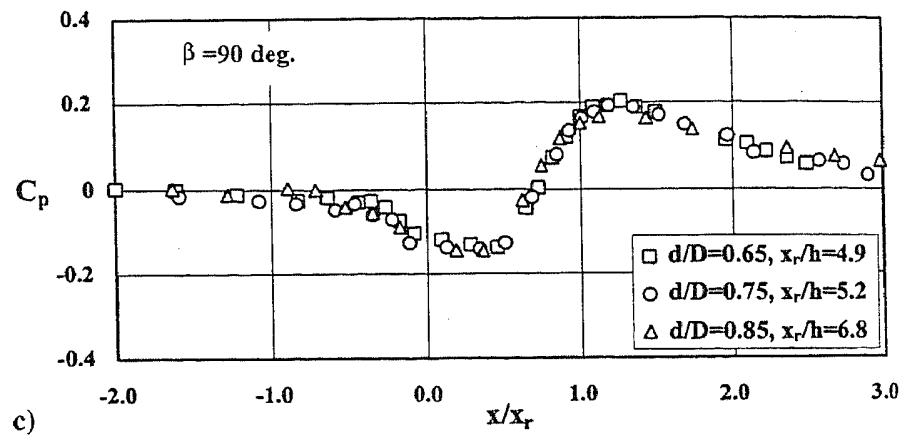

Fig. 9 Effect of diameter ratio on surface-pressure distributions, $M_{\infty}=0.8$.

of diameter ratio for type II flows (with the origin for the $x$ axis at the separation point along the boat-tail as opposed to the boat-tail corner). The pressure distributions are similar except at $\beta=15 \mathrm{deg}$, $d / D=0.85$ at $M_{\infty}=1.0$, for which the pressure changes in the boat-tail zone are small (Fig. 11a) for the reasons described earlier.

\section{Effect of Freestream Mach Number}

For type I flow, two families of pressure distributions were observed; typical results are shown in Fig. 12 for the case of $\beta=31.5 \mathrm{deg}$. The data at $M_{\infty}=0.7,0.8$, and 0.9 were closer to each other, whereas the data at $M_{\infty}=1.0$ and 1.2 had broadly similar characteristics in the separated and pressure recovery region. The surface pressures following separation at the boat-tail corner are generally lower at $M_{\infty}=1.0$ and 1.2 (compared to $M_{\infty}=0.7$, 0.8 , and 0.9 ) because the flow approaching the corner is mildly supersonic and therefore encounters an expansion fan. In contrast, the surface-pressure distributions for type II flow did not exhibit similarity (Fig. 13), indicating stronger effect of Mach number; the $C_{p}$ values in the separated flow region for type II flows were relatively lower as compared to type I flows.

\section{Features of Unsteady Pressure Distributions} RMS Pressure Distributions

The unsteady features of surface pressure were obtained at selected streamwise locations on each model configuration with emphasis on the reattachment zone. The rms pressure levels in the attached turbulent boundary layer $(x=-30 \mathrm{~mm})$ showed good comparison $^{6}$ with the experiments of Coe made at NASA Ames Research Center in the 14-ft transonic wind tunnel. ${ }^{1}$ Figures 14 and 15 show typical results of the effect of $d / D$ and $\beta$ (respectively) on $C_{\text {prns }}$ at $M_{\infty}=0.8$. Some of the interesting features observed for type I flow include 1) occurrence of the maximum value of rms pressure fluctuation in the vicinity of shear-layer reattachment (Fig. 14) 


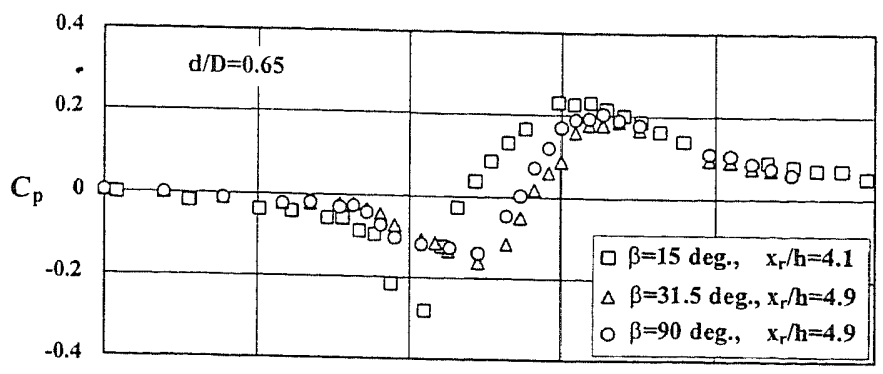

a)

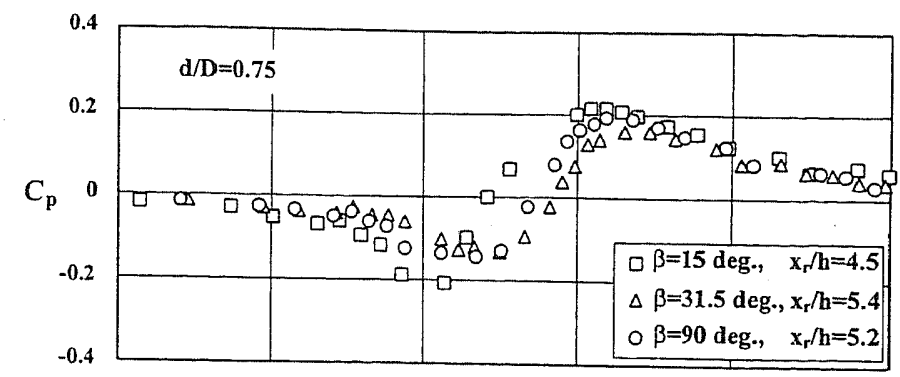

b)

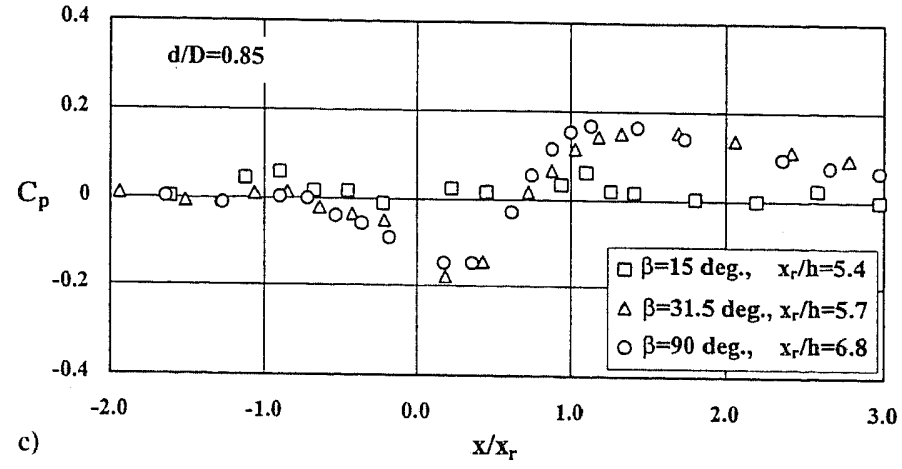

Fig. 10 Effect of boat-tail angle on surface-pressure distributions, $M_{\infty}=0.8$.

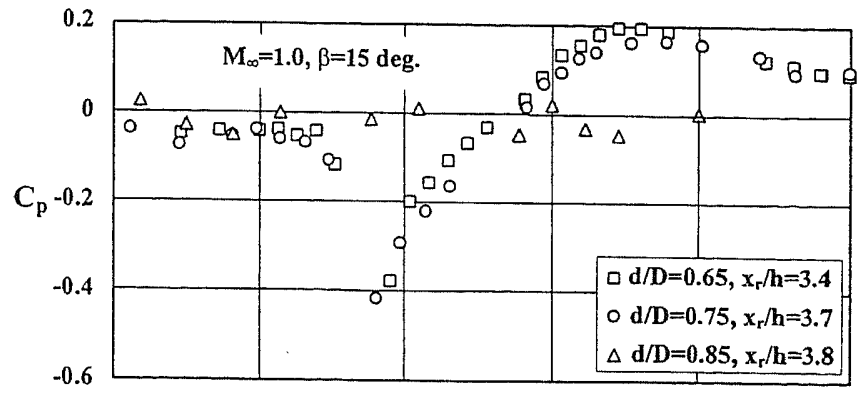

a)

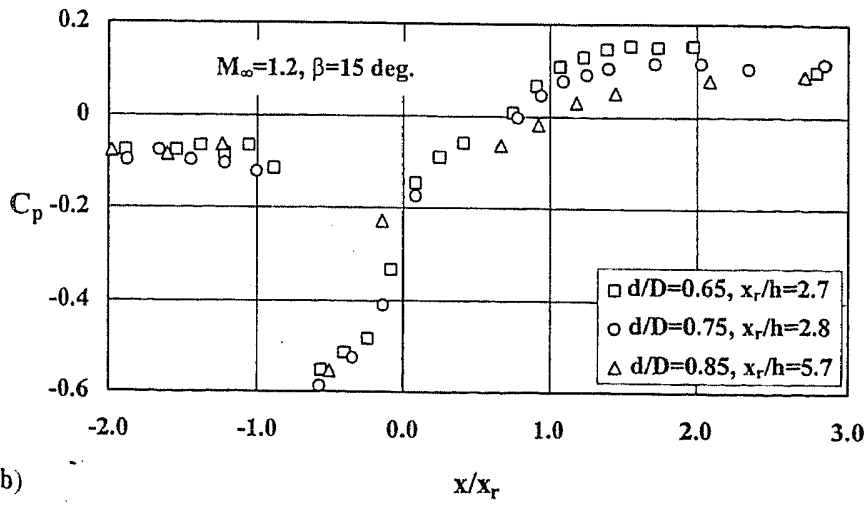

Fig. 11 Effect of diameter ratio on surface-pressure distributions in shock-induced separation.

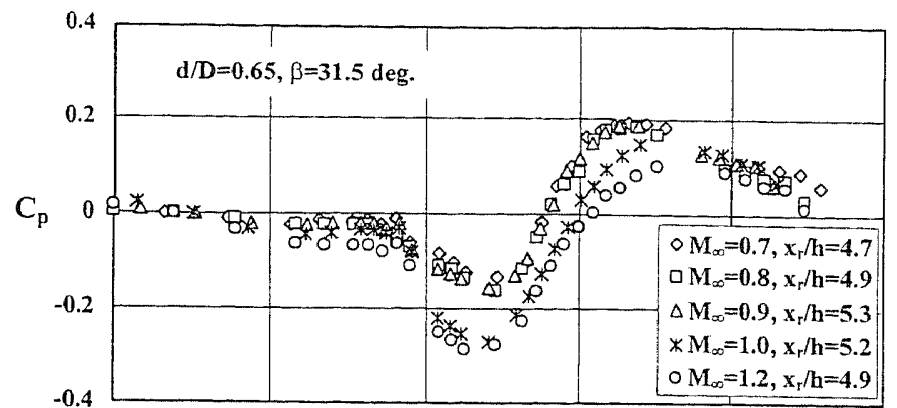

a)

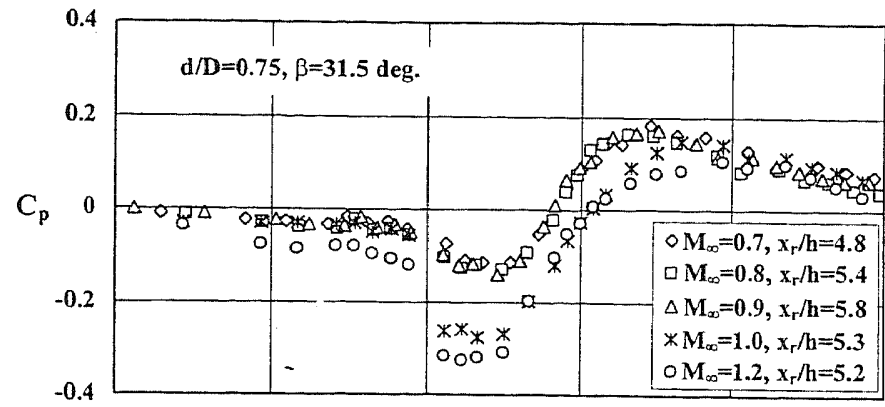

b)

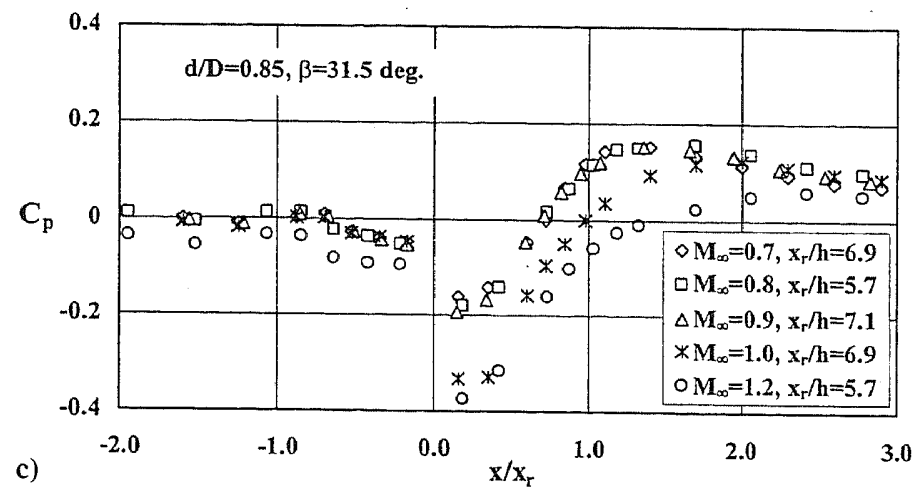

Fig. 12 Effect of freestream Mach number on surface-pressure distributions.

as found in earlier investigations ${ }^{14,15} ; 2$ ) a systematic trend generally involving an increase in the value of $C_{\text {prms }}$ with step height (or a decrease in $d / D$ ) (Fig. 14); 3) similarity in the streamwise distributions of $C_{\text {prms }}$ for $\beta=31.5$ and $90 \mathrm{deg}$ (Fig. 15), as seen with the mean surface-pressure distributions (Fig. 10); and 4) a progressive decrease both in maximum value as well as the value corresponding to attached boundary layer with an increase in freestream Mach number ${ }^{6}$ (reflecting progressive increase in the dynamic pressure in the tunnel). Qualitatively similar results were observed at other Mach numbers. ${ }^{6}$ For type II flows, two peaks in $C_{\text {prons }}$ (Fig. 16), corresponding to separation and reattachment locations were seen similar to the observations made in supersonic separated flows ${ }^{2}$; the peak value at separation was about twice higher than at reattachment.

\section{Typical Spectra of Pressure Fluctuations}

Typical amplitude spectra of surface-pressure fluctuations corresponding to type I flow (Fig. 17) reveal the following features: 1) the spectra in the vicinity of reattachment has higher energy levels (about twice) up to a frequency of about $6 \mathrm{kHz}$ than the attached boundary layer, 2) the energy level in the separated bubble is negligible because the local dynamic head is very low, and 3 ) there is no evidence of any periodicity in the reattachment zone. For type II flow involving shock-induced separation (Fig. 18), the shock spectrum showed a steep slope and high intensities at low frequencies (as observed in supersonic separated flows in the vicinity of the shock wave ${ }^{2}$ ); the reattachment spectrum was similar to those observed for type I flows (Fig. 17). 


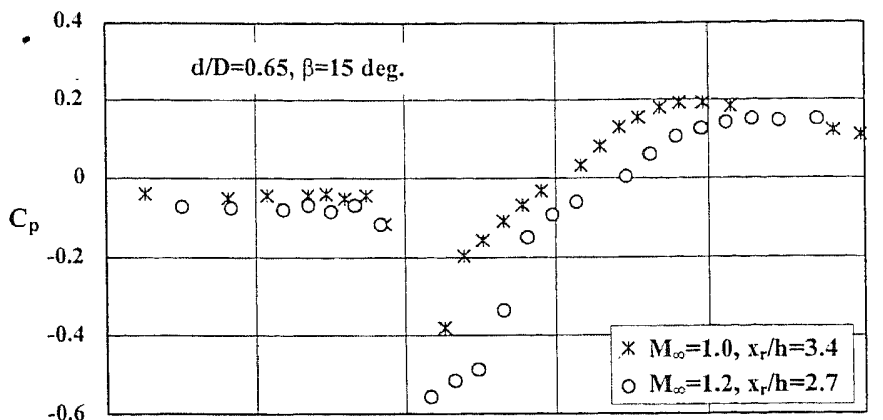

a)

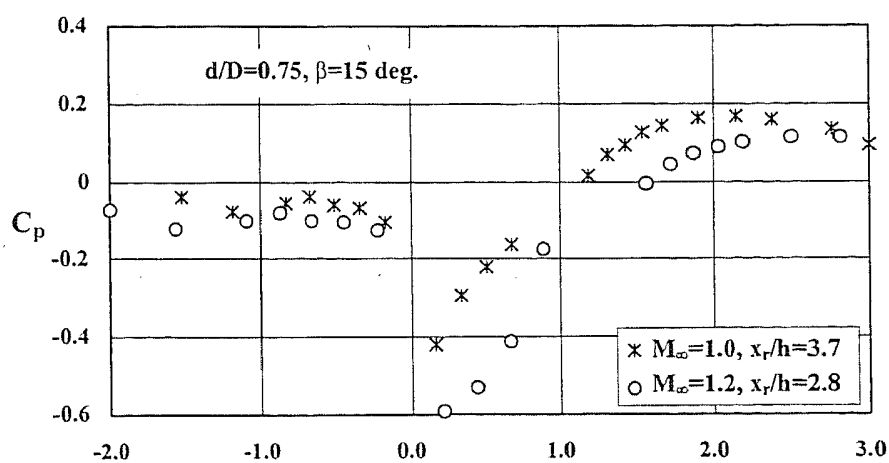

b)

Fig. 13 Effect of freestream Mach number on surface-pressure distributions in shock-induced separation.

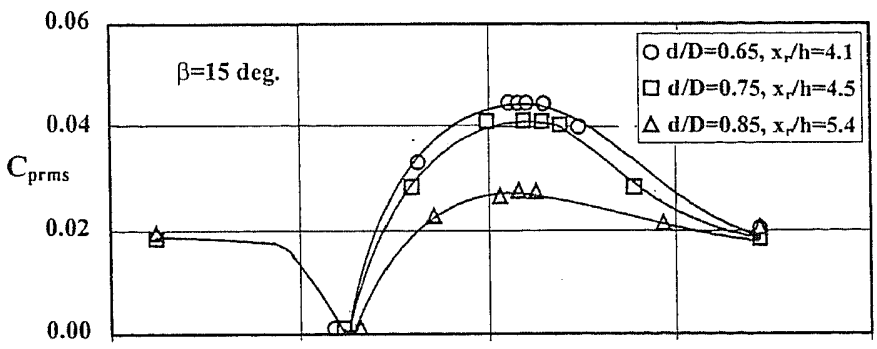

a)

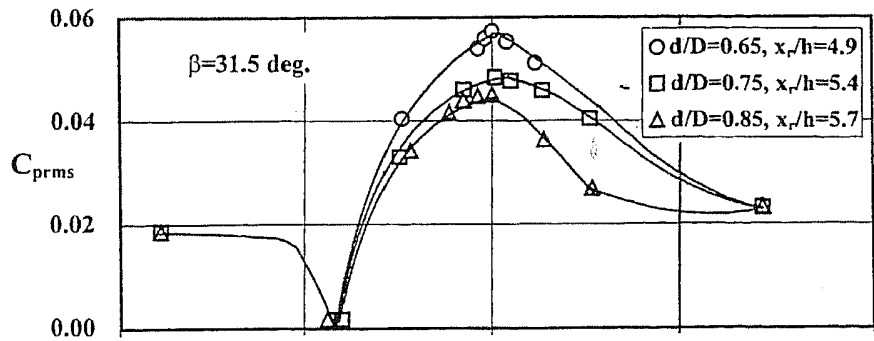

b)

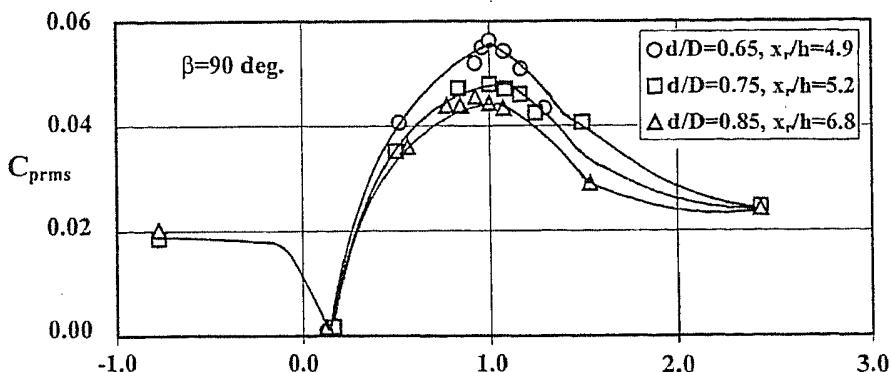

c)

Fig. 14 Effect of diameter ratio on rms pressure fluctuations, $M_{\infty}=0.8$.

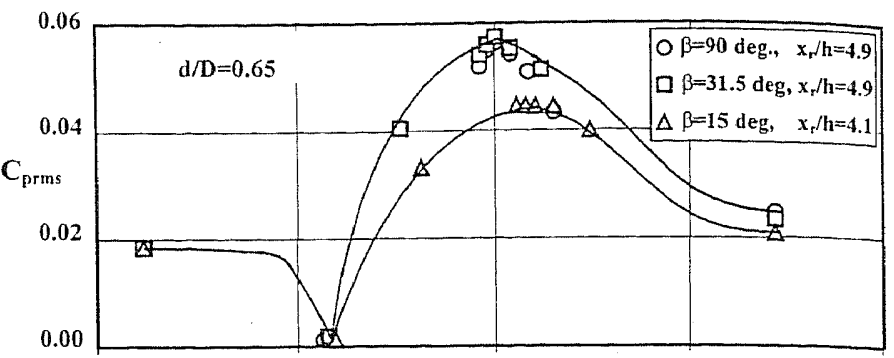

a)

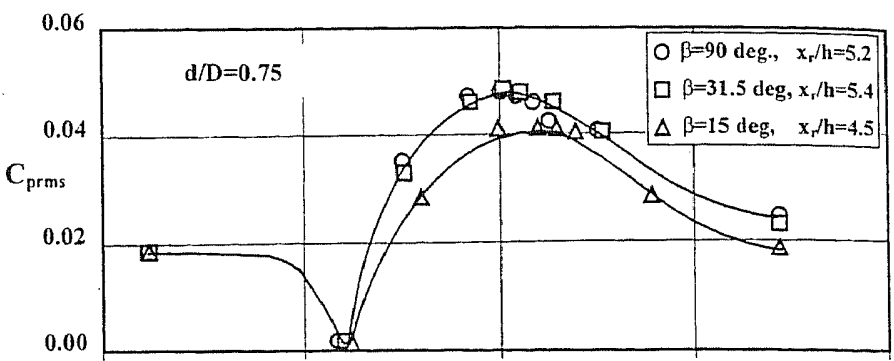

b)

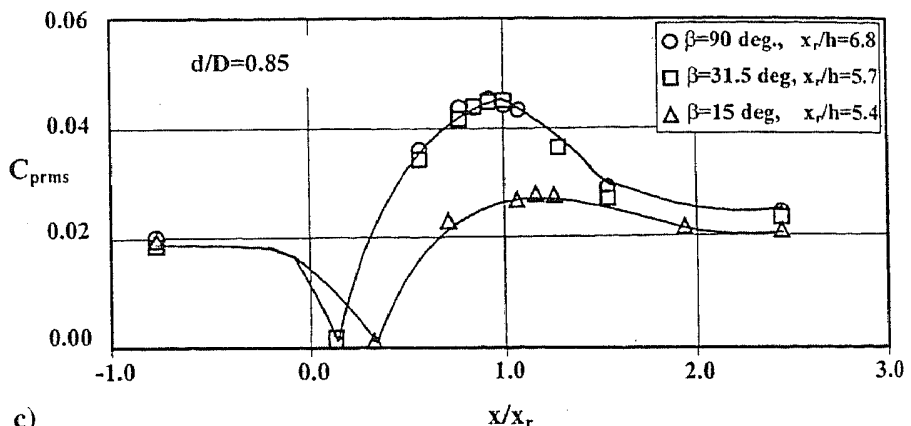

Fig. 15 Effect of boat-tail angle on $\mathrm{rms}$ pressure fluctuations, $M_{\infty}=0.8$.

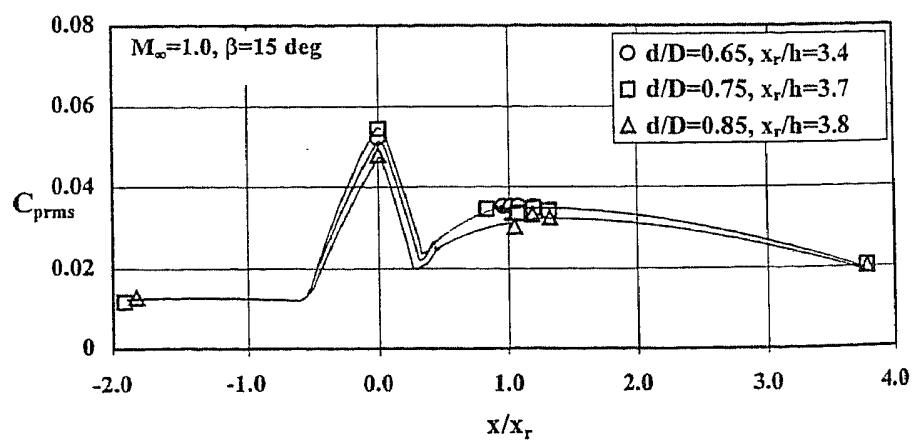

Fig. 16 Effect of diameter ratio on rms pressure fluctuations in shockinduced separation.

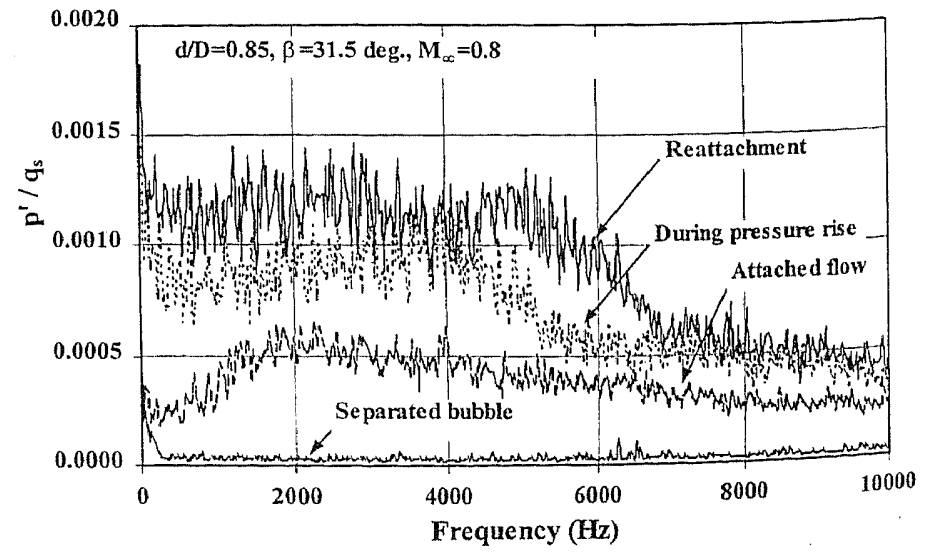

Fig. 17 Typical spectra of pressure fluctuations for type I flows. 


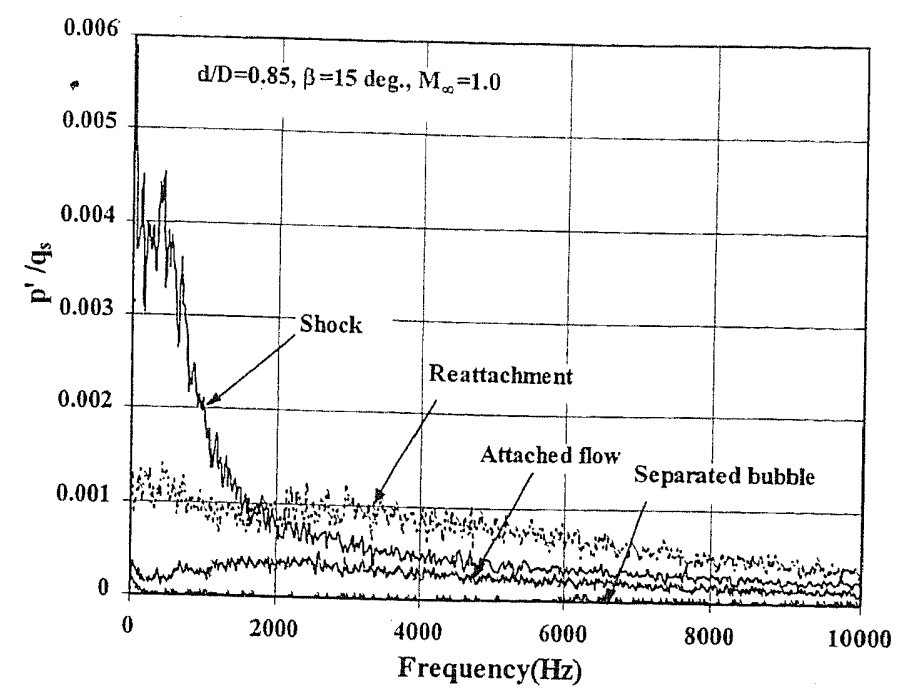

Fig. 18 Typical spectra of pressure fluctuations for type II flows.

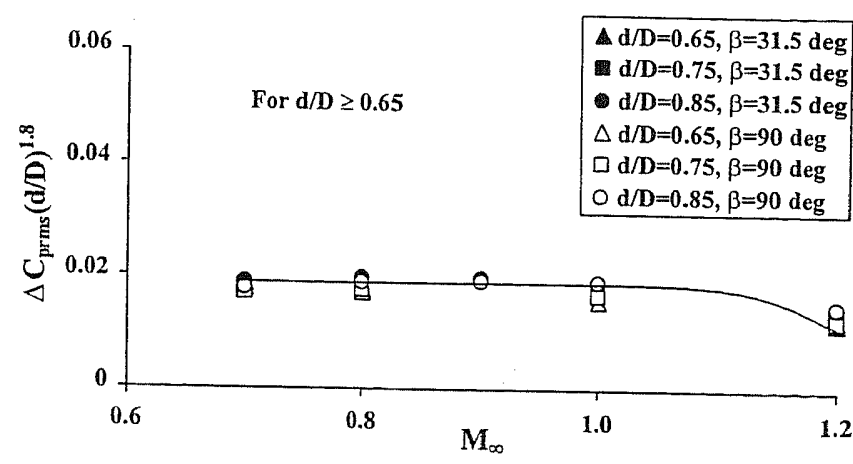

Fig. 19 Correlation for the maximum rms pressure fluctuations.

$\begin{array}{lcccc} & d / D & \beta & M_{\infty} & \\ \text { Rajan et al } & 0.85 & 31.5 \mathrm{deg} . & 0.8 & \square \text { Launch vehicle } \\ \text { Present } & 0.85 & 31.5 \mathrm{deg} . & 0.8 & - \text { Generic } \\ \text { Coe } & 0.70 & 30.0 \mathrm{deg} . & 0.8 & \square \text { Launch vehicle } \\ \text { Present } & 0.75 & 31.5 \mathrm{deg} . & 0.8 & \square \text { Generic }\end{array}$

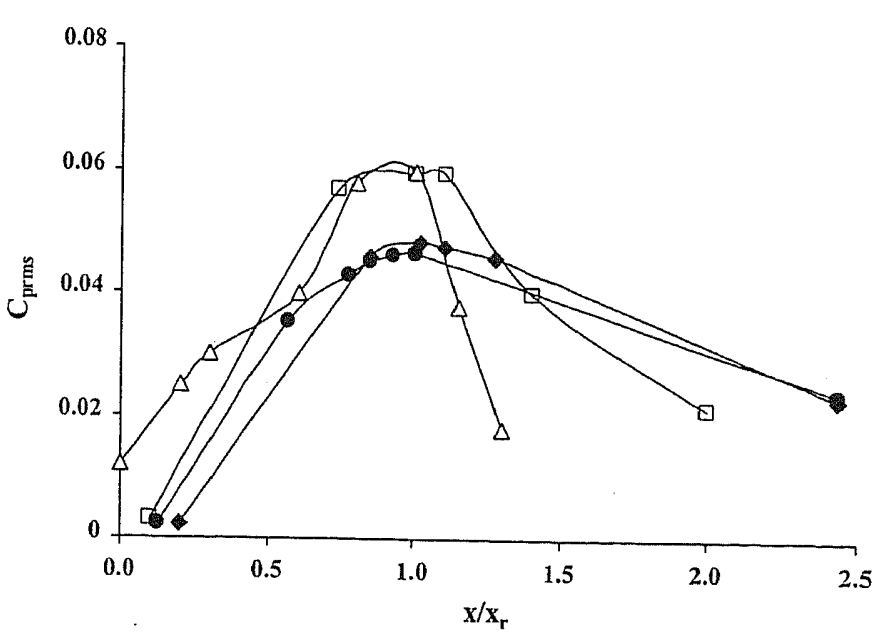

Fig. 20 Comparison of present data with launch vehicle-type configurations.

Correlation for the Maximum Value of $C_{\text {prms }}$

Based on the measurements made, a correlation is suggested for the maximum value of rms pressure fluctuation in the reattachment zone at different freestream Mach numbers. Figure 19 shows the correlation in which the difference in the $C_{\text {proms }}$ at reattachment and attached boundary layer (at each Mach number) is plotted against $M_{\infty}$. The preceding correlation involves the important geometrical and flow parameters of the problem.
Comparison of ims Le'vels with Launch Vehicle Configurations

Figure 20 shows a comparison of $C_{\text {prns }}$ with $x / x$, obtained on the generic configuration in the present tests with those on launch vehicle type configurations. ${ }^{1.15}$ The different cases compared in Fig. 20 correspond to type I flow and the value of geometrical parameters and $M_{\infty}$ are very close to each other making the comparisons very relevant. The results indicate that the maximum values of $C_{\text {prms }}$ on launch vehicle configurations involving bulbous or hammerhead nose are much higher (about $35 \%$ ) than those obtained in the present tests on a generic configuration with a well-developed turbulent boundary layer ahead of boat-tail corner. It seems likely that the higher levels of $C_{\text {prms }}$ in the reattachment zone are associated with distorted turbulent boundary layers ahead of the boat-tail corner in launch vehicle designs, which result from the strong streamwise pressure gradients and shock-wave boundary-layer interaction in the nose region.

\section{Conclusions}

With a view to gain further understanding of mean and unsteady surface-pressure field associated with boat-tail separated flows relevant to launch vehicle configurations, a detailed parametric study was carried out at trarsonic Mach numbers. The effects of diameter ratio and boat-tail angle were systematically studied in the $M_{\infty}$ range of $0.7-1.2$. The present study, possibly the first attempt with emphasis on the reattachment zone, has resulted in a broad understanding of mean flow features, surface-pressure fluctuations, and their similarity at transonic speeds. In particular, the results show that the maximum level of surface-pressure fluctuations occur in the vicinity of shear-layer reattachment for different configurations, as found in some of the earlier investigations. A comparison of the data on rms surface-pressure fluctuations in the reattachment zone of launch vehicle-type geometry (available in the literature) with the present results on a generic configuration shows that bulbous or hammerhead nose shapes generate much higher levels, which are probably a result of distorted turbulent boundary layers ahead of the boat-tail corner in such designs. The database generated in the present study has resulted in a useful correlation for the maximum value of $C_{\text {prms }}$, which would be valuable in the development of engineering methods for the calculation of unsteady loads relevant to launch vehicle-type configurations.

\section{Acknowledgments}

The authors sincerely thank the Aeronautical Research and Development Board, Government of India, for funding the research program. Rajan Kumar sincerely thanks S. N. Seshadri, H. Sundramurthy, and V. Kanagarajan for their encouragement and support during the course of investigation. Thanks are due to the $0.6-\mathrm{m}$ tunnel staff and National Trisonic Aerodynamic Facilities model shop for their valuable help during wind-tunnel testing and model fabrication.

\section{References}

${ }^{1}$ Coe, C. F., "The Effect of Some Variations in Launch Vehicle Nose Shape on Steady and Fluctuating Pressure at Transonic Speeds," NASA TMX-646, March 1962.

${ }^{2}$ Coe, C. F., and Dods, J. B., Jr., "Crossflow Effects on Steady and Fluctuating Pressures on an Ogive Cylinder Cone Frustum Model in Supersonic Separated Flow," NASA TP-1951, July 1981.

${ }^{3}$ Cole, A. E., and Stanley, W. T., "Dynamic Response of a Hammerhead Launch Vehicle Wind Tunnel Model," NASA TM-104050, June 1991.

${ }^{4}$ Rainey, A. G., "Progress on the Launch Vehicle Buffeting Problem," Journal of Spacecraft and Rockets, Vol. 2, No. 3, 1965, pp. 289-298.

${ }^{5}$ Sundra Murthy, H., Verma, R. S., Jagdeeshwarachar, S. P., and Rajan Kumar, "Flow Quality Improvements in a Blowdown Wind Tunnel," Journal of Aircraft, Vol. 38, No. 3, 2001, pp. 577-580.

${ }^{6}$ Rajan Kumar, "Mean and Fluctuating Pressure Field in Boat-Tail Separated Flows at Transonic Speeds," M.S. Thesis, Dept. of Aerospace Engineering, Indian Inst. of Science, Bangalore, India, Dec. 1999.

${ }^{7}$ Kline, S. J., and McClintock, F. A., "Describing Uncertainties in SingleSample Experiments," Mechanical Engineering, Vol. 75, Jan. 1953, pp. 3-8.

${ }^{8}$ So, R. M. C., and Zhang, H. S., "Logarithmic Laws for Compressible Turbulent Boundary Layers," AIAA Journal, Vol. 32, No. 11, 1994, pp. 2162-
2168.

${ }^{9}$ Ginoux, J. J., "Separated Supersonic Flows," Proceedings of the 1960 Heat Transfer and Fluid Mechanics Institute, edited by D. M. Mason, Stanford Univ., Stanford, CA, 1960, pp. 179-191. 
${ }^{10}$ Green, J. E., "Reflexion of an Oblique Shock Wave by a Turbulent Bo indary Layer," Journal of Fluid Mechanics, Vol. 40, Pt. 1, 1970, pp. 8195.

${ }^{11}$ Korst, H. H., "A Theory of Base Pressures in Transonic and Supersonic Flow," Journal of Applied Mechanics, Vol. 23, 1956, pp. 593600.

${ }^{12}$ Hastings, R. C., "Turbulent Flow Past Two-Dimensional Bases in Supersonic Streams," Aeronautical Research Council, R \& M 3401, London, Dec. 1963.

${ }^{13}$ Roshko, A., and Thomke, G. J., "Observations of Turbulent Reattachment Behind an Axisymmetric Downstream-Facing Step in Supersonic Flow," AIAA Journal, Vol. 4, No. 6, 1966, pp. 975-980.
${ }^{14}$ Mabey, D. G., "Pressure Fluctuations Caused by Separated Bubble Flows at Subsonic Speeds," Royal Aircraft Establishment, RAE-TR-71160, Bedford, England, U.K., Dec. 1971.

${ }^{15}$ Rajan Kumar, Sundara Murthy, H., and Prasada Rao, K., "Unsteady Pressure Measurements in the Heat Shield Region of a Typical Launch Vehicle Configuration," Journal of Aeronautical Society of India, Vol. 49, No. 1 , 1997, pp. 15-20.

\title{
Gossamer Spacecraft: Membrane and Inflatable Structures Technology for Space Applications
}

\author{
Christopher H. M. Jenkins, South Dakota School of Mines and Technology; editor
}

Written by many experts in the field, this book brings together, in one place, the state of the art of membrane and inflatable structures technology for space applications.

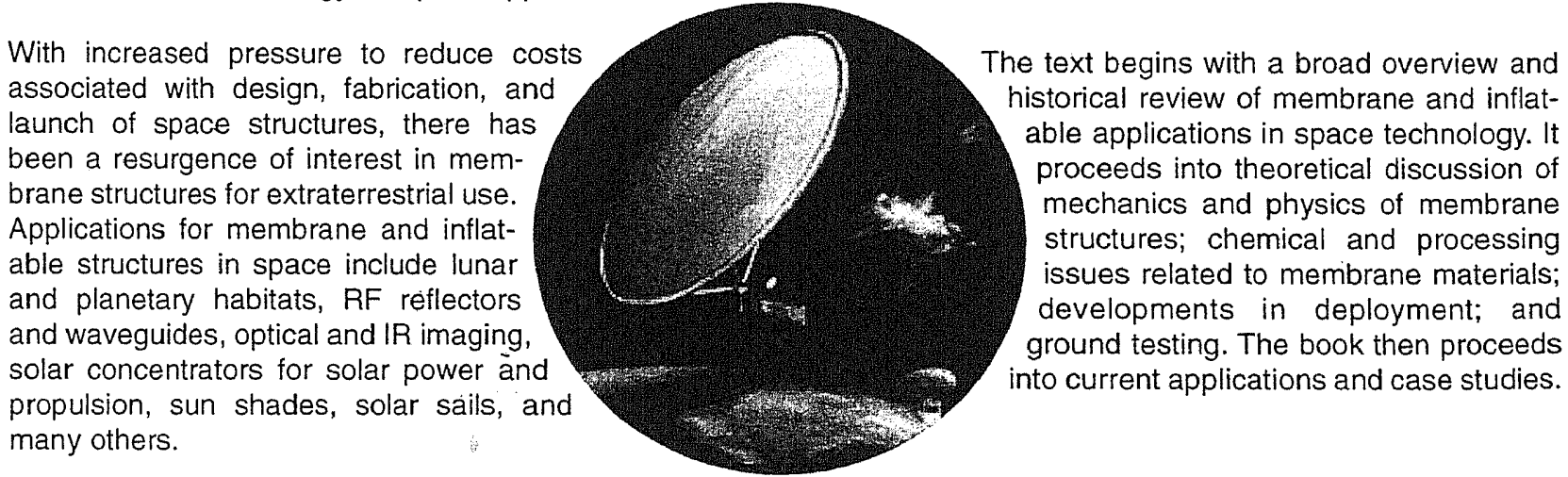

Progress in Astronautics and Aeronautics 5 List Price: $\$ 84.95$ AlAA Member Price: $\$ 59.95$ 2001, 586 pp, Hardcover •ISBN 1-56347-403-4 Source: 945

\section{AIAA.}

American institute of Aeronautics and Astronautics Publications Customer Service, 9 Jay Gould Ct., P.0. Box 753, Waldorf, MD 20604 Fax 301/843-0159 Phone 800/682-2422 E-mail aia@@tasco1.com 8 am-5 pm Eastern Standard Time

Order 24 hours a day at www.aiaa.org
CA and VA residents add applicable sales tax. For shipping and handting add $\$ 4.75$ tor 1-4 books (call tor rales for higher quantities). All individual orders-including U.S., Canadian, and ioreign一must be prepaid by personal or cornpany check, traveler's check, internalional money order, or credit card (VISA, MaslerCard, American Express, or Diners Club). All checks must be made payable to AIAA in U.S. doltars, drawn on a U.S. bank. Orders trom, libraries, corporations, government agencies, and universily and college bookslores must be accornpanied by an authorized purchase order. All other bookstore orders muss be prepaid. Please allow 4 weeks lor delivery. Prices are subject to change withoul notice. Returns in sellable condition wilt be accented within 30 days. Sorry. we cannol accept returns of case studies, conlerence proceedings, sale iltems, or software (unless defeclive). Non-U.S. residenils are responsibte for payment of any laxes required by their governnent. 